\title{
A Study of Fingerprints in Relation to Gender and Blood Group among Residents of Maiduguri, Nigeria.
}

\author{
A.U. Ekanem, H. Abubakar and N. I. Dibal \\ (Department of Human Anatomy, University of Maiduguri, P. M. B. 1069, Maiduguri, Borno State, Nigeria.)
}

\begin{abstract}
Fingerprints are classified and documented on the basis of ridge patterns. The impressions made by the pattern of any individual remain unchanged throughout life. The study was carried out on 400 individuals among which 200 were males and 200 were females subjects having different ABO blood groups, all the 10 fingerprints were divided into loops, whorl and arches. The results showed that majority of the subjects belonged to blood group $O$. The finger print pattern of loops had the highest frequency while arches were the least. Blood group $O$ were mostly associated with the loop pattern while $A B$ had the least frequency in all the fingerprint patterns. Males had the highest number with the loops and whorls while females had the highest number of arches. It was concluded that there was an association between distribution of fingerprint patterns, blood group and gender and thus prediction of gender and blood group of a person was possible based on the fingerprint patterns.
\end{abstract}

Keywords: Blood group, Fingerprints, Gender, Pattern, Relation.

\section{Introduction}

The skin is marked by "carved works" especially on the palms and soles. The pattern of these markings on the fingers is called dermatoglyphics [1]. In dermatoglyphics, the impressions made by the minute ridge patterns have exactly the same arrangement and the pattern of any individual remain unchanged throughout life. These features statistically differ among sexes, ethnic groups and age categories [2]. Fingerprints may be classified and documented on the basis of ridge pattern, setting up an identification system that is almost infallible [3].

Human finger prints fall into three main groups: loops, whorls and arches. Loops are the most common type, accounting for approximately $65 \%$ of all fingerprints. They are formed by ridge lines that flow in from one side of the print, sweep up in the center like a tented arch and then curve back around and flow out on the side where they entered. Loops are designated as being either radial or ulnar, depending on which side of the finger the lines enter. Whorls account for approximately $30 \%$. They consist of four different patterns; the plain whorl, central pocket loop, the double loop and accidental whorl [4]. Their common features are that they have at least two deltas and one or more ridge line curves around the core to form a circle or spiral. The accidental whorl can be any pattern or combination of patterns that do not fit into any of the above classifications [5]. Arches are the simple pattern but rare (about 5\%). They are of two types; plain and tented arches. In both types the ridge lines flow into the print from one side, rise in the middle of the pattern and flow out to the other side of the print. Despite these broad patterns, each individual has a unique set of prints which can be used as a means of personal identification [4]. Other evidences used for identification includes DNA profiling, lip marks, foot prints, bite marks, etc.

Blood group system was discovered way back in 1901 by Karl Landsteiner. It consists of mainly the 'ABO' and 'Rhesus' groups. The 'ABO' system is further classified as $\mathrm{A}, \mathrm{B}, \mathrm{AB}$ and $\mathrm{O}$ blood group types according to presence of corresponding antigen in plasma. 'Rhesus' system is classified into Rhesus Positive (Rh $+\mathrm{ve})$ and Rhesus Negative ( $\mathrm{Rh}-\mathrm{ve})$ according to the presence or absence of ' $\mathrm{D}$ ' antigen [6]. The aim of this study was to investigate the relationship between different types of finger prints with blood group and gender and also to determine the distribution of different fingerprint patterns among individuals in Maiduguri, Nigeria.

\section{Materials and Methods}

Materials used were ink pad, magnifying lens, Anti-serum A, B, and D, tiles, blood samples, cotton wool, methylated spirit and sterile lancets. A total of 400 adults (200 Males and 200 Females) between 18-35 years voluntarily participated in the study. The study was conducted within Maiduguri metropolis, Borno State, Nigeria as well as the University of Maiduguri campus. Volunteers with permanent scars on one or more fingers and those with any hand deformity either due to injury or birth defect were excluded from the study.

The procedure for blood collection and finger prints was explained to each subject after which the subject was asked to press the finger on the ink pad and then to the plain sheet of paper to transfer the finger print. The same method was repeated for all the fingers of both hands. While taking the finger prints of each individual, care was taken to avoid sliding of fingers to prevent smudging of the print. Blood sample was 
collected by pricking the finger with a sterile lancet after cleaning it with methylated spirit. A drop of blood from each subject was mixed with Anti-serum A, Anti-serum B and Anti-serum D on a clean tile. Blood groups were determined on the basis of presence or absence of agglutination. The gender and age of each subject are noted and the fingerprint patterns were analyzed and identified as loop, whorls and/or arches, based on the appearance of the ridge lines with the help of a magnifying lens.

\section{Results}

The results of the distribution of blood group are showed in Table 1 . The majority of the subjects belong to blood group $\mathrm{O}+\mathrm{ve}(58.25 \%)$, followed by $\mathrm{B}+\mathrm{ve}(15.75 \%)$ and $\mathrm{A}+\mathrm{ve}(15 \%)$. There were no subjects with blood groups $\mathrm{A}-\mathrm{ve}$ and $\mathrm{AB}-\mathrm{ve}$. Group $\mathrm{O}+\mathrm{ve}$ was predominant among males $130(32.5 \%)$ while $\mathrm{O}+\mathrm{ve}$ and $\mathrm{A}+\mathrm{ve}$ were predominant among females $103(25.72 \%)$ and $42(10.5 \%)$, respectively. The males and females had approximately equal number of B + ve. The males were $31(7.75 \%)$ while the females were 32 $(8 \%)]$.

The distributions of pattern of fingerprint in relation to blood groups are showed in Table 2. The loop pattern has the highest frequency $2241(56 \%)$ followed by whorls $1232(30.8 \%)$, while arches had the least 527 $(13 \%)$. Blood group $\mathrm{O}$ had the highest number of loops followed by blood group B and A. The group AB has the least frequency in all the fingerprint patterns.

Table 3 shows the distribution of fingerprints in relation to gender. Males had the highest number of loops $1240(31 \%)$ and whorls $652(16.3 \%)$ compared with that of the females $1000(25 \%)$ and $580(14.5 \%)$, respectively; while the females had the highest number of arches $328(8.2 \%)$ compared to the males $200(5 \%)$.

\section{Discussion}

The study showed that in Maiduguri metropolis, rhesus +ve have the highest number of individuals with blood group $\mathrm{O}+\mathrm{ve}$ having more than $50 \%$ of the population. The general distribution of blood groups was of the same order with that of the present study population. That is highest frequency of $\mathrm{Rh}+\mathrm{ve}$ and lowest frequency of $\mathrm{Rh}-\mathrm{ve}$; highest frequency of Blood group $\mathrm{O}$ and lowest blood group $\mathrm{AB}$. These results were similar in distribution among the Indian Population $[6,7]$.

Blood group $\mathrm{O}$ has the highest frequency of all fingerprint patterns in Maiduguri while $\mathrm{AB}$ had the least. In the distribution of fingerprint pattern within Maiduguri metropolis, males had the highest number of loops and whorls while females had the highest number of arches though they were the rarest fingerprint patterns. This is similar to the study conducted among 30 African Americans which showed that African American females had a higher incidence of loops and arches whereas African American males had a higher incidence of whorls [8].

In all blood groups, the frequency of finger print pattern showed that loops were the most common pattern followed by whorls while arches were the least occurring pattern among residence of Maiduguri metropolis. These distribution patterns were also obtained among Indian subpopulations and African Americans $[6,9,10]$.

Table 1: Distribution of Subjects According to Blood Groups and Gender

\begin{tabular}{lllllllll}
\hline & \multicolumn{2}{l}{ Blood Group A } & \multicolumn{2}{c}{ Blood Group B } & \multicolumn{2}{c}{ Blood Group AB } & \multicolumn{2}{c}{ Blood Group O } \\
& Rh+ve & Rh - ve & Rh +ve & Rh -ve & Rh +ve & Rh -ve & Rh +ve & Rh-ve \\
\hline Male & $18(4.50)$ & $0(0)$ & $31(7.75)$ & $2(0.50)$ & $13(3.25)$ & $0(0)$ & $130(32.50)$ & $6(1.50)$ \\
Female & $42(10.50)$ & $0(0)$ & $32(8.00)$ & $3(0.75)$ & $12(3.00)$ & $0(0)$ & $103(25.75)$ & $8(2.00)$ \\
Total & $60(15.00)$ & $0(0)$ & $63(15.75)$ & $5(1.25)$ & $15(6.25)$ & $0(0)$ & $233(58.25)$ & $14(3.50)$ \\
\hline
\end{tabular}

Figures in parenthesis indicate percentage, $\mathrm{Rh}=$ Rhesus, $+\mathrm{ve}=$ Positive, $-\mathrm{ve}=$ Negetive.

Table 2: Distribution of Patterns of Fingerprint in finger of Both Hands in Relation to Different Blood Groups

\begin{tabular}{llllll}
\hline & Blood Group A & Blood Group B & Blood Group AB & Blood Group O & Total \\
\hline Loops & $400(10.00)$ & $464(11.60)$ & $149(3.73)$ & $1228(30.70)$ & $2241(56.00)$ \\
Whorls & $191(4.80)$ & $229(5.73)$ & $92(2.30)$ & $720(18.00)$ & $1232(30.80)$ \\
Arches & $83(2.10)$ & $97(2.43)$ & $46(1.15)$ & $301(7.53)$ & $527(13.200)$ \\
\hline
\end{tabular}

Figures in parenthesis indicate percentage.

Table 3: Distribution of Patterns of Fingerprint in Finger of Both Hands in Relation to Gender

\begin{tabular}{lllll}
\hline & Male & Percentage (\%) & Female & Percentage (\%) \\
\hline Loops & 1240 & 31.00 & 1000 & 25.00 \\
Whorls & 652 & 16.30 & 580 & 14.50 \\
Arches & 200 & 5.00 & 328 & 8.20 \\
\hline
\end{tabular}




\section{Conclusion}

Conclusively, there was an association between distribution of fingerprint patterns, blood group and gender in Maiduguri and thus prediction of gender and blood group of a person is possible based on fingerprint pattern.

\section{References}

[1]. G. M. Bhat, M. A. Mukhdoomi, B. A. Shah and M. S. Ittoo, Dermatoglyphics: in health and disease - a review, International Journal of Research in Medical Sciences 2(1), 2014, 31-37.

[2]. S. S. Gornale, C. D. Geetha, and R. Kruth, Analysis of Fingerprint Image for Gender Classification. American International Journal of Research in Science, Technology, Engineering \& Mathematics 1(1), 2013, 46-50.

[3]. V. J. Pillay, Textbook of Forensic Medicine and Toxicology (15 ${ }^{\text {th }}$ Ed. Hyderabad: Paras Medical publishers, 2009$)$, 53-94.

[4]. T Kanchan, and S. Chaltopadhyay, Distribution of Fingerprint Among Medical Students. Journal of Indian Academy of Forensic Medicine 28(2), 1996, 65-68.

[5]. K Vij, Textbook of Forensic Medicine and Toxicology ( $3^{\text {rd }}$ Edition, New Delhi: Elservier, 2005), 89-91.

[6]. D Bhavana, J. Ruchi, T. Prakash, and J. L. Kalyan, Study of Fingerprint pattern in Relation with Blood Group and Gender - A Statistical Review, Research journal of Forensic Sciences 1(1), 2013, 15-17.

[7]. S. K. Rolati, K. A. Shah, V. C. Patel, A. K. Menat, R. N. Mori, N. K. Chaudhari, An Effort to Determine Blood Group and Gender from Pattern of fingerprints National Journal of Community Medicine 4(1), 2013, 158-160.

[8]. L Wang, and C. A. Alexander, Study of Fingerprints in Relation to Gender and blood group. Journal of Indian Academy of Forensic Medicine, 32(1), 2010, 11-14.

[9]. P Rastogi, and K. R. Pillai, A Study of Fingerprints in Relation to Gender and blood Group. Journal of Indian Academy of Forensic Medicine, 32(1), 2010, 11-14.

[10]. M. R. Sangam, A. R. Babu, K. Krupadanam , and K. Anasuya, Fingerprint Pattern in Different Blood Groups. Journal of Indian Academy of Forensic Medicine, 33(40), 2011, 343-345. 